\title{
Complexity, Habits and Evolution
}

\author{
Geoffrey M. Hodgson
}

2009

The Business School, University of Hertfordshire, De Havilland Campus, Hatfield, Hertfordshire AL10 9AB, UK www.geoffrey-hodgson.info g.m.hodgson@herts.ac.uk

University of Hertfordshire Business School Working Papers are available for download from https://uhra.herts.ac.uk/dspace/handle/2299/619

The Working Paper Series is intended for rapid dissemination of research results, workin-progress, and innovative teaching methods, at the pre-publication stage. Comments are welcomed and should be addressed to the individual author(s). It should be remembered that papers in this series are often provisional and comments and/or citations should take account of this.

Copyright and all rights therein are retained by the author. All persons copying this information are expected to adhere to the terms and conditions invoked by each author's copyright. These works may not be re-posted without the explicit permission of the copyright holders.

The Business School at the University of Hertfordshire (UH) employs approximately 150 academic staff in a state-of-the-art environment located in Hatfield Business Park. It offers 17 undergraduate degree programmes, 21 postgraduate programmes and there are about 80 research students, mostly working at doctoral level.

Business School staff are active in research in numerous areas, including complexity theory, institutional economics, economic modelling, efficiency measurement the creative industries, employment studies, finance, accounting, statistical methods and management science.

The University of Hertfordshire has been recognised as the exemplar of a business-facing university. It is one of the region's largest employers with over 2,700 staff and a turnover of $£ 205 \mathrm{~m}$.

In the 2008 UK Research Assessment Exercise it was given the highest rank for research quality among the post-1992 universities. 


\title{
Complexity, Habits and Evolution
}

\author{
Geoffrey M. Hodgson \\ The Business School, University of Hertfordshire, De Havilland Campus, Hatfield, \\ Hertfordshire AL10 9AB, UK \\ www.geoffrey-hodgson.info \\ g.m.hodgson@,herts.ac.uk
}

For The SAGE Handbook of Complexity and Management

\section{Introduction}

This article addresses what are often described as 'complex adaptive systems.' Typically such systems involve populations of entities that store and replicate information. But these micro aspects are less fully explored in most accounts, which concentrate on macro-outcomes of complex adaptive systems, particularly self-organisation and emergent properties. These omissions are addressed here, with a stress on the roles of individual habits and organisational routines. It is argued that such considerations open up the possibility of a meta-theoretical evolutionary framework for understanding complex adaptive systems. This essay also makes use of some insights from evolutionary and institutional economics and contrasts its approach with some standard assumptions in mainstream economics.

The growing appreciation of the complexity of social as well as natural phenomena has promoted a diversity of responses, especially within the social sciences, including varieties of relativism, post-modernism and post-structuralism (Morçöl 2001). Important ideas within the complexity narrative include self-organisation, autopoiesis, emergent properties, requisite variety, non-linearity, path dependence, positive feedback, chaotic behaviour, and so on. But while these are important concepts, neither singly nor jointly do they amount to a unifying theory of complex phenomena.

Is such a theory possible? Paul Cilliers (1998, p. ix) claims that complexity itself rules out such an over-arching theory. Notably his argument would apply to natural as well as social phenomena. Yet despite the complexity of the natural world, scientists have made 
considerable progress in developing explanatory frameworks and theories, even if the task of prediction is often confounded by complexity. To take an example, while the human body is highly intricate, successful curative medicine is possible.

Stephen Wolfram (2002) argues that complex phenomena can be generated by simple, algorithmic rules. While the outcomes are often unpredictable because of nonlinearities, their understanding and explanation centres on the generative algorithms or programs. A danger here is the conflation of reality with a computer simulation. Simple algorithms can give rise to complex outcomes but that does not mean that the complexity we find in reality has an equivalent and equally simple origin.

The apparent absence of an unifying theoretical framework has encouraged the sceptics. One of these is John Horgan (1995) who critiqued the original claims of some complexity theorists (including those at the Santa Fe Institute) that they were in sight of a grand unifying theory of complex phenomena.

I agree with Horgan that such a grand unifying theory is very far from our grasp. Its elevation to a major objective is a symptom of a tendency to excessive generalisation that has caused serious problems, at least in the social sciences. Among these is the neglect of historical and other specific phenomena and their specific roles and dynamics. Much of postwar economics and sociology has been diverted into a competitive quest for ever-greater generality and abstractness, to the reckless neglect of specific phenomena (Hodgson 2001). Despite the generation of a number of important insights, it is increasingly acknowledged that there is no unified and coherent narrative worthy of the title of 'complexity theory' (Anderson 1999, Marion 1999).

But both advocates and critics of 'complexity theory' have been diverted by universalities. The advocates have hunted for general principles that might apply to slime moulds, piles of sand, tree leaves, chemical reactions, astronomical bodies, weather systems and much else, including all human organisations and societies. Their very limited success is the cue for the critics, some of whom bemoan the failure to come up with anything remotely like Newton's laws or the general theory of relativity.

Any theorisation of complexity applied to human societies or organisations, addresses a specific set of phenomena. We consider some of the very basic features of this set and establish that they apply to a large class of natural phenomena as well. Furthermore, it is then possible to establish some general principles that apply to this broader domain. But the nature of these principles is very different from the aforementioned 'laws' that have been established in physics.

I am concerned with complexity in human society. Consequently, I start the argument with the human agent, placed in a social and natural context, interacting with others. The ontological and epistemic complexity of this configuration is acknowledged. I then point to some basic cognitive and behavioural mechanisms that are necessary to deal with this complexity. There are some related but very different mechanisms in the natural world. There are also related mechanisms at the higher level of social organisation. These communalities at three different levels point to some limited over-arching principles relevant to all complex systems in this broad class. But before I outline the nature of these principles it is necessary to dispense with some rival claims, such as the universality and sufficiency of self-organisation theory. Once this is done I make a specific claim concerning the evolutionary character of most complex adaptive systems. This claim is well over a hundred years old, but it is relatively neglected, and some theorists may find it surprising. 


\section{Adaptive populations}

Much of the work carried out under the rubric of complexity research makes quite specific ontological assumptions. Much of 'complexity theory' addresses not complex phenomena in general, but a particular form of complexity typically described by John Holland (1992), Brian Goodwin (1994), Stuart Kauffman (1995), Ralph Stacey (1996, 2003) and many others as a 'complex adaptive system'. In practice, such systems are made up of multiple interconnected entities. In complex adaptive systems theory a number of agents interact with each other and together form a system that adapts to its environment. Also the individual entities are adaptive in that they have the capacity to change or learn from interaction and experience. A central question is: how do such complex non-linear systems function to produce ordered and novel patterns of behaviour, in the absence of any overall blueprint or ruling designer? We are dealing not merely with singular wholes, but with populations of adaptive agents that interact with others and form structured relations, which themselves adapt through time.

Consider the basic nature and capacities of these agents. In real circumstances they need inputs of matter or energy to survive. They face a complex and changing social and natural environment, posing vital problems that require solutions. They can not only replicate and pass on some of their capacities and physical characteristics, but also they can communicate useful knowledge and techniques. This broad description applies to human society and to a large number of types of natural and artificial phenomena: but it is not universal. By sacrificing its universalist objective and specifying a particular ontology, complexity theory can make significant further progress.

The predominant emphasis on the literature on complexity has been on the structure and adaptations of the system as a whole and not on the individual components. The explanatory focus has been on the possible emergence without design of organisation and orderly patterns of behaviour. This agenda is important and valuable. But it is one-sided. The emphasis has been on the complexity of the system, rather on the complexity of the components, their environments, and the adaptive problems that they face. Discourses on self-organisation, spontaneous order and autopoiesis acknowledge the interacting components, but often perhaps in the pursuit of universal explanations - fail to consider adequately their particular characteristics and micro-contexts.

I propose to bend the stick in the other direction. I shall concentrate first on the interacting agents and their complex environments. Macro-systemic considerations will be brought in later.

The next section briefly reviews the treatment of agents and their environments in mainstream economics. After revealing various limitations, we consider contrasting approaches in dealing with complexity in the section after that.

\section{Hyper-rationality in mainstream economics}

Although mainstream economists urge us to take individuals and their incentives seriously, in their pursuit of the 'science of choice' they have overlooked the complexity of the decision environment, and the limitations of human cognitive and communicative capacities when faced with this complexity. They have assumed that individuals can perform immense feats of deliberation and calculation, or that it is legitimate to assume that individuals act 'as if' they had such capacities. It is only since the 1990s that these assumptions have been successfully 
contested on mainstream terrain, despite the longstanding complaints of several heterodox critics including Thorstein Veblen (1898) and the Nobel Laureate Herbert Simon (1957).

Even today, with significant mainstream acknowledgement of 'bounded rationality', contrary ideas remain entrenched in some quarters. The rational expectations hypothesis is still widely used in economic models: it assumes that outcomes do not differ systematically from what people expected them to be, and that people have the mental capacity to process all available information,. Significantly, some influential challenges to this hypothesis have used insights from chaos theory. Non-linearities make predictions by agents difficult or impossible (Akerlof and Yellen 1985, Grandmont 1987). The rational expectations hypothesis is also challenged by models where a small minority of agents are not fully rational. Outcomes can diverge radically from models where agents all have equivalent rational capacities (Haltiwanger and Waldman 1985).

Despite all its emphasis on the individual, mainstream economics often assumes that individual preferences are similarly structured or identical, and that information-processing capacities are equivalent. Relaxation of these assumptions often leads to a breakdown of mainstream results (Arrow 1986).

Furthermore, although economists have relaxed the 'perfect information' assumptions of earlier decades, to embrace various forms of incomplete or imperfect information, cognitive divergences are rarely acknowledged. The 'Harsanyi doctrine' is still commonplace: this attributes differences in individuals' beliefs entirely to differences in information and upholds that every individual interprets information in the same way. Yet in reality cognitive divergences are typical. That is one reason why conversation and communication are important. They help (with limited success) to overcome different interpretations and establish some common meanings. Cognitive divergence is an important facet of the complexity that we all face in social interactions, yet the Harsanyi doctrine assumes it away.

Game theory is at the cutting edge of mainstream economics. One form of game theory assumes not only that agents are rational, but also they know and fully take into account the rationality of others: this is the 'common knowledge of rationality' assumption. But some game theorists have moved away from this supposition of hyper-rational agents, with theoretical results that are strikingly different from those where common knowledge of rationality is assumed (Gintis 2000, Camerer 2003).

Overall, mainstream economics has only partially moved away from assumptions of agent rationality and homogeneity. Where such moves have been made, they have led to very different results. Mainstream economics has half-opened the Pandora's Box of complexity but does not know how to keep its contents under control.

\section{The nature of habit}

Contrasting assumptions are found in non-mainstream thought, including within evolutionary and institutional economics. By contrast, these approaches start from the assumptions of heterogeneous agents, cognitive divergence, and complex interaction. Known forms of mathematical analysis meet barriers of intractability in such circumstances, and consequently one has to fall back on indicative theorising including agent-based computer models, case studies and historical research.

Rather than starting a priori from relatively simple models of rational individuals and trying to draw logical conclusions from their assumptions, these approaches rely much more 
heavily on psychological and cognitive research to understand how boundedly rational agents deal with uncertainty and complexity. The work of William James (1890) is highly relevant here. He founded a school in psychology that stresses the role of habits in dealing with complexity and uncertainty. His work inspired evolutionary and institutional economists such as Veblen $(1898,1914)$, philosophers such as John Dewey (1922) and is enjoying a renaissance today (Johnson and Henley 1990, Plotkin 1994).

Instincts are inherited biologically. By contrast, habits are conditional propensities moulded by environmental circumstances and transmitted culturally rather than biologically. The mechanisms of habit are largely unconscious, but they may press on our awareness. Habits are submerged repertoires of potential behaviour; they can be triggered or reinforced by an appropriate stimulus or context. The meaning of habit adopted by James (1890), Veblen (1898) and Dewey (1922) was of an acquired proclivity or capacity, which may or may not be actually expressed in current behaviour. A similar interpretation of habit as a disposition is found in the work of contemporary psychologists (Ouellette and Wood 1998, Wood et al. 2002, Wood and Neal 2007).

Brain imaging studies on human subjects (Poldrack et al., 2001) show that the formation of habits involves a shift away from parts of the brain associated with conscious, declarative memory and goal-setting (the medial temporal lobe and pre-frontal cortex) towards areas associated with procedural memory and context-triggered responses (the basal ganglia).

This conception of habit contrasts with that used by some other authors. For example, the Nobel economist Gary Becker (1992, p. 328) wrote: 'I define habitual behavior as displaying a positive relation between past and current consumption'. Becker here defines habit not as a behavioural propensity but as sequentially correlated behaviour. In contrast, the view of habit here is of a disposition, which, once acquired, is not necessarily realised in any future behaviour. Habit is a causal mechanism, not a set of correlated events. Repeated behaviour is important in establishing a habit. But if we acquire a habit we do not necessarily use it all the time.

\section{Habits and complex environments}

In terms of energy requirements, the brain is very expensive. While it accounts for less than two per cent of our weight, it consumes up to twenty per cent of our calorific intake (Drubach 2000). Bigger brains mean that we have to consume more calories, and our ancestors had to spend more time on hunting and gathering. The evolution of the human brain was a trade-off between its survival advantages and its energy costs.

Rather than trying to amass and process all information, habit is a much cruder way of storing information from past experience. It vastly economises on brain storage capacity. Habit crudely encapsulates past adaptive behaviour: much information is not retained. The capacity to form habits has evolved in humans to cope with complex changing environments with large amounts of information, given the limited capacity and energy costs of the human brain.

The role of habit is illustrated by an agent-based computer simulation developed by Thorbjørn Knudsen and myself (Hodgson and Knudsen 2004a). The simulation considers the evolution of a traffic convention, concerning whether to drive on the left or right side of a circular track. Agents make decisions through weighted combinations of 'rational deliberation' on current information and habitual dispositions to drive on one side rather than 
the other. The most important result of these simulations concerns the effect of introducing habit into the modelling of agent behaviour. In most of parameter space, strength of habit can increase the systemic rate of convergence towards a left/right convention. In some circumstances it can also enhance systemic resistance to error. In short, habit helps agents to deal with uncertainty, complexity and change. It requires less mental storage capacity than fully rational deliberation.

Another computer simulation that illustrates the role of habits (or similar rule-like behavioural dispositions) in complex environments was performed by Giovanni Dosi, Luigi Marengo, Andrea Bassanini and Marco Valente (1999). Their work addresses the computability and complexity of the decision procedures of agents. Instead of taking an axiomatic approach grounded on the principles of rationality and optimisation, they use algorithms where decisions are evolving outcomes of processes of learning and adaptation to the particular environment in which the decision must be made. They apply genetic programming (Koza 1992) to agent behaviour in oligopolistic markets. Consistent with evidence of the behaviour of real economic agents, the simulation shows that the response to complexity is often to increase the reliance on behaviour driven by relatively simple rules.

Both simulations establish that the higher the ratio between the complexity of the environment, on the one hand, and the informational and deliberative capacities of agents, on the other, the more that agents have to rely on something like habit, and the more efficacious it becomes in the circumstances. Habit is a vital psychological mechanism to deal with complexity and change.

Often acquired through cultural transmission, habits serve as means of learning skills and fixing useful knowledge in human societies. Anthropologists Peter Richerson and Robert Boyd (2001) have argued that human capacities to develop and transmit a sophisticated culture evolved during periods of rapid climate change, when the relatively rapid transmission of useful knowledge on how to adapt to the environment was vital. Biologically inherited instincts have important uses, but they change far too slowly to accommodate new knowledge in complex and changing environments.

Without habits our brains cannot deal with the vast amounts of information involved. For example, when using a language, we cannot deliberate upon every element. Such calculations would bring discourse to a halt. We have to rely on acquired habits to deal with standard linguistic rules, so that the brain is freed up to contemplate higher-level decisions. Similar remarks apply to all human skills of thought or behaviour. In a complex world, habit is a necessary foundation for our knowledge and skills.

\section{From habits to organisational routines}

In everyday parlance the word 'routine' is used loosely to refer to repeated sequences of behaviour, by individuals as well as by organizations. But when Richard Nelson and Sidney Winter (1982) used the concept in their seminal work on economic and organizational evolution, and repeated the metaphor of 'routines as genes', they suggested a more specific and technical meaning for the term. It is important to clarify and refine this technical meaning.

A consensus has now emerged that routines relate to groups or organizations, whereas habits relate to individuals (Cohen et al. 1996, Dosi et al. 2000). Individuals have habits; groups have routines. But routines do not simply refer to habits that are shared by many individuals in an organization or group. Routines are not themselves habits: they are 
organizational meta-habits, existing on a substrate of habituated individuals in a social structure. Routines are one ontological layer above habits themselves.

Nelson and Winter (1982) refer repeatedly to 'routines as genes'. This is another useful analogy. But of course, as these authors emphasise, routines are very different from genes. Routines do not replicate biologically and they are much less enduring. All analogies are inexact in some respects and must be handled with care. The gene analogy usefully points to routines as relatively durable carriers of information through shorter periods of time, with the capacity to generate particular outcomes in given circumstances. Routines are like genes in the abstract sense that they are both generative, rule-like structures and potentialities.

Contrary to some ambivalence in the literature, routines (like habits) are best treated as stored behavioural capacities or capabilities rather than behaviour as such (Hodgson 2008). Consider a firm in which all employees and managers work between 9am and 5pm only. During this working day a number of organizational routines can be energized. At other times the firm is inactive. But the routines do not all disappear at 5pm, to reappear mysteriously the next day. The routines-as-capacities remain, as long as the individuals have the potential and disposition to work again together in the same context. Subject to this condition, the routines can be triggered the next day by appropriate stimuli.

Routines energize a series of conditional, interlocking, sequential behaviours among individuals within the organization (Cohen and Bacdayan 1994). Routines depend upon a structured group of individuals, each with particular habits, where many of these depend upon procedural memory. The behavioural cues by some members of a structured assembly of habituated individuals triggers specific habits in others. Hence various individual habits sustain each other in an interlocking structure of reciprocating individual behaviours. Together these behaviours take on collective qualities associated with teams. The organization or group provides a structured social and physical environment for each individual, including rules and norms of behaviour, of both the explicit and the informal kind. This environment is made up of the other individuals, the relations between them and the technological and physical artefacts that they may use in their interactions. This social and physical environment enables, stimulates and channels individual activities, which in turn can help trigger the behaviour of others, produce or modify some artefacts, and help to change or replicate parts of this social and physical environment.

Hence organizations have important additional properties and capacities that are not possessed by individuals, taken severally. The organization provides the social and physical environment that is necessary to enable specific activities, cue individual habits and deploy individual memories. If one person leaves the organization and is replaced by another, then the new recruit may have to learn the habits that are required to maintain specific routines. Just as the human body has a life in addition to its constituent cells, the organization thus has a life in addition to its members. The additional properties of the whole stem from the structured relations and causal interactions between the individuals involved (Blitz 1992, Hodgson 2004, Weissman 2000).

The above discussion has established that, in addition to genes at the biological level, there are additional information-carrying mechanisms in human societies, namely habits at the individual level and routines at the organisational level. An abstract communality exists, despite huge differences at the level of detail. The significance of this point will be developed later. But we are already hinting at the possibility of extending the use of Darwinian principles beyond the biological sphere. 


\section{Self-organisation versus Darwinism?}

Emergent properties are a facet of 'self-organisation'. Organisations have undesigned properties that are not features of individuals, taken severally. Let us tackle the relationship between self-organisation and Darwinism, before elaborating the relevance of the latter and returning to the role of habits and routines.

Much has been written on how our knowledge of complexity should modify the Darwinian theory of evolution, particularly through the acknowledgement of the role of self-organisation (Depew and Weber 1995). Some interpreters of this work go so far as to suggest that selforganization provides an alternative to Darwinian theory. These interpretations are mistaken, both in terms of their misunderstanding of the claims of leading theorists of self-organisation, and in the viability of their claim.

Self-organization may be necessary to explain the emergence of a number of complex phenomena. But in the absence of selection there is little chance of the development of increasingly complex structures. Thus, rather than being alternatives, Kauffman (1993, p. 465) saw a 'natural marriage of self-organization and selection.' He and several other pioneers of self-organization theory do not present their argument as an alternative to Darwinian theory. Jeffrey Wicken (1987) wrote of 'extending the Darwinian paradigm,' not exterminating it. David Depew and Bruce Weber (1995) considered 'Darwinism evolving,' not Darwinism abandoned. Weber and Depew (1996, p. 51) wrote:

the very concept of natural selection should be reconceived in terms that bring out its dynamical relationships with chance and self-organization. In our view, Kauffman's recent work, as expressed in The Origins of Order, does just this.

What is involved here is a revision and extension of natural selection theory, not its negation. Kauffman (1995, p. 8) himself called for a 'revision of the Darwinian worldview' not its abandonment. As Kauffman (1993, p. 644) also related:

I have tried to take steps toward characterizing the interaction of selection and selforganization. ... Evolution is not just 'chance caught on the wing.' It is not just a tinkering of the ad hoc, of bricolage, of contraption. It is emergent order honored and honed by selection.

Once self-organized systems and subsystems emerge, natural selection acts upon these selforganized structures once they emerge. Far from being an alternative to natural selection, selforganization requires it in order to determine which self-organized units have survival value. Accordingly, other self-organization theorists, such as the biologists Scott Camazine and his colleagues, similarly recognize that self-organization complements rather than displaces the 'orthodoxy' of natural selection. Echoing Kauffman, Camazine et al. (2001, p. 89) write,

There is no contradiction or competition between self-organization and natural selection. Instead, it is a cooperative 'marriage' in which self-organization allows tremendous economy in the amount of information that natural selection needs to encode in the genome. In this way, the study of self-organization in biological systems promotes orthodox evolutionary explanation, not heresy.

Consequently, evolutionary economists who propose that self-organization theory is an alternative to Darwinian principles are at variance with their prominent mentors in selforganization theory. Leading theorists of self-organization recognize that natural selection is required at some point in the explanation. 
Crucially, an exclusive focus on self-organization concentrates on the development of the entity, neglecting its interactions with its environment and providing no adequate explanation of how the entity comes to be adapted to survive in this environment (Cziko 1995). The mistake is to concentrate entirely on internal development and evolution from within, even to the extent of defining evolution in these narrow and unwarranted terms.

On the contrary, in biology, neither individuals, species, nor ecosystems are entirely 'selftransforming.' Evolution takes place within open systems involving both endogenous and exogenously stimulated change. Generally, evolution takes place both through internal changes and interactions with the (possibly changing) environment.

\section{The Darwinian evolution of complex adaptive systems}

Darwin himself $(1859$, pp. 422-3, 1871, vol. 1, pp. 59-61, 106) hinted at the possibility that his core principles might apply to other evolving systems, such as human language. This insight was taken up by others in the nineteenth century (Ritchie 1896, Veblen 1899) revived later in the twentieth century (Campbell 1965), but is only recently receiving wider attention.

Theorists working in this area suggest that in typical 'complex adaptive systems' Darwinian core principles are not only relevant but ultimately unavoidable. Importantly, there is no adequate rival over-arching theory to deal with these systems.

Most 'complex adaptive systems' involve populations of adaptive agents that interact with others and form structured relations, which themselves adapt through time. To emphasise their population properties, they are described elsewhere as 'complex population systems' (Hodgson and Knudsen 2006, Aldrich et al. 2008).

By definition, entities in complex population systems face specific problems that have to be solved to minimize degradation and raise the chances of survival. In short, these entities are engaged in a struggle for existence, to use the term adopted by Darwin (1859, pp. 62-63).

We also assume some capacity to retain and pass on to others workable solutions to problems faced in the struggle for existence. Examples include tools and technological knowhow. Retaining such problem solutions or adaptations means avoiding the risks and labour of learning them anew. Given that the entities in the population are mortal and degradable, there are also good reasons to assume that some capacity exists to pass on to others information about such workable solutions. This is the basis of the Darwinian principle of inheritance.

In sum, a complex population system involves populations of non-identical (intentional or non-intentional) entities that face locally scarce resources and problems of survival. Some adaptive solutions to such problems are retained through time and may be passed to other entities. Examples of such complex population systems are plentiful both in nature and in human society. They include the ensembles of every biological species, from amoebas to humans. In addition, they include collections of human organisations such as business firms, as long as these organisations are cohesive entities with a capacity to retain and replicate problem solutions.

Crucially, an adequate explanation of the evolution of such a system must involve the three Darwinian principles of variation, inheritance and selection. These are the broad Darwinian theoretical requirements. They do not themselves provide all the necessary details, but nevertheless they must be honoured. Otherwise the explanation of evolution will be inadequate. 
Consider the three Darwinian principles in turn. Each principle is an explanatory requirement. First, there must be some explanation of how variety is generated and replenished in a population. In biological systems the answers - established since Darwin's death - involve genetic recombination and mutations. By contrast, the evolution of social institutions involves innovation, imitation, planning and other mechanisms very different from the detailed processes found in biology (Aldrich and Ruef 2006). The general problem of the existence and replenishment of variety remains a vital question of evolutionary research in the social and technological domain (Metcalfe 1998, Nelson 1991, Saviotti 1996). Innovations are a common source of new variation, but the determinants of such novelties are not fully understood.

Second, there must be an explanation of how useful information concerning solutions to particular adaptive problems is retained and passed on. This requirement follows directly from the broad nature of the complex population system that we are required to explain, in which there must be some mechanism by which adaptive solutions are copied or passed on. In biology these mechanisms often involve genes and DNA. In social evolution we may include the replication of habits, customs, rules and routines, all of which may carry solutions to adaptive problems (Veblen 1899, Nelson and Winter 1982, Hayek 1988). There must be some mechanism that ensures that some such solutions (embodied in habits, routines or whatever) endure and replicate; otherwise the continuing retention of useful knowledge would be impossible.

Third, and not least, there must be an explanation of the fact that entities differ in their longevity and fecundity. In given contexts, some entities are more adapted than others, some survive longer than others, and some are more successful in producing offspring or copies of themselves. Here the principle of selection comes in. Selection involves an anterior set of entities, each interacting with its environment and somehow being transformed into a posterior set where all members of the posterior set are sufficiently similar to some members of the anterior set, and where the resulting frequencies of posterior entities depend upon their properties in the environmental context (Price 1995, Andersen 2004, Knudsen 2004). Through selection, a set of entities, a population, will gradually adapt in response to the criteria defined by an environmental factor. Thus in a cold environment, the proportion of mammals with more fat or long fur is likely to increase.

The principle of selection is different from the principle of variation. The latter is the requirement for some explanation of the sources and replenishments of variety. Selection refers to the mechanisms that bring about the survival of some variations rather than others, often reducing variety. Even when both variety-creation and selection involve human agency, as often is the case in the human domain, the two processes are quite different. Innovation is about the creation of new variations; selection is about how they are tested in the real world.

Note that outcomes of a selection process are necessarily neither moral nor just. Furthermore, there is no requirement that outcomes of a selection process are necessarily optimal or improvements on their precursors. Insofar as these outcomes carry connotations of refinement or efficiency, it is efficiency relative to the given environment, and efficiency that is tolerable rather than optimal. Darwinism does not assume that selection brings about globally efficient or (near) optimal outcomes, and in certain instances selection can even lead to systematic errors (Hodgson 1993). There is no reason to believe that the special requirements needed to asymptote global efficiency are generally prevalent in nature or society (Winter 1964, Gould 2002). 
Without honouring the principle of selection, we have no way of explaining how some entities or their offspring prevail over others. The principle is widely held to apply in the natural world; the fitter members of the species often have greater chances of survival and procreation. This helps to explain how species become adapted to their environment. But the move from the natural to the social world does not undermine the principle of selection. Even if there is not a fierce life-and-death struggle between rival customs or institutions, some explanation is required of why some enjoy greater longevity than others, why some are imitated more than others, and why some diminish and decline. Any such explanation must come under the general rubric of selection, as defined above.

Darwin's principles of variation, inheritance and selection are required not only to explain evolution within populations but also the origins of those populations themselves. Overall, as long as there is a population with imperfect inheritance of their characteristics, not all of them having the same potential to survive, then Darwinian evolution will occur.

\section{Conclusion: habits, routines and Darwinian evolution}

If Darwinian principles apply to social as well as biological entities, then we need to search for the appropriate units of selection, replication and variation at the social level. Richard Dawkins (1976) suggested the 'meme' as the answer, vaguely defined as ideas, brain patterns or behaviours. But even if becomes fashionable, the coining of a new word does not solve the problem of explaining the mechanics of social evolution. The 'meme' beholds more problems than it gives answers.

Recent work in the philosophy of social and biological evolution (Sterelny et al. 1996, Godfrey-Smith 2000, Hull et al. 2001) has established general definitions of the common abstract units and processes in Darwinian evolution. Developing and using these definitions, Thorbjørn Knudsen and myself (Hodgson and Knudsen 2004b, 2006) have established that psychological or organisational entities such as habits or routines can be treated as replicators, and organisations such as business firms can be treated as 'interactors' (Hull 1988) - the generalisation of the phenotype concept in biology. This work brings us closer to a 'genetics' of social evolution, but the detailed mechanisms involved are very different from those found in the biological domain.

Generally, organisms, individuals or organizations develop mechanisms to acquire, retain and enact relatively simple heuristics or 'rules of thumb' to cope with complexity. Among such mechanisms are (biologically inherited) instincts, (culturally inherited) habits and (culturally transmitted) routines within organizations. These 'simple heuristics that make us smart' (Gigerenzer and Todd 1999) economise hugely on both memory and computational capacity, and they can be replicated relatively easily. A disadvantage is that they are relatively rigid and difficult to adjust. The more complex and adaptive entities develop higher-order habits or routines to scrutinise lower-order habits or routines. In society as well as nature, a further means by which instincts, habits or routines adjust in a population of entities is by the selective demise of organisms, individuals or organizations that fail to adapt to their environment, or to discover or create suitable niches for survival.

In sum, the Darwinian approach provides an over-arching framework for further theoretical and empirical exploration into the detailed mechanisms involved in learning, knowledge transfer, organisational competition, and organisational change. 
Note that complexity comes into this account in at least two important ways. Accounts of complex adaptive systems rightly emphasise the complexity of the interactions between entities, the existence of emergent properties as a result of their interaction, and the unpredictability of outcomes. This is complexity largely from a macro perspective.

Less prominent in the complexity literature are discussions of the complexity facing agents and the psychological or other mechanisms that are required to deal with it. In the approach to social evolution summarised here, individual habits and organisational routines are different replicators and part of the multilevel evolutionary process in society.

In a Darwinian framework, social evolution is addressed simultaneously from both a macro and a micro perspective. This dual micro-macro approach raises new questions concerning complexity. Both natural and social evolution have led to the emergence of highly complex phenomena. In human society in particular the complexity of social organisation has increased vastly in the last few hundred years.

We know that in the biological sphere genetic information changes only very slowly. By contrast, habits are much more malleable. Individual habits can be formed in response to institutional and cultural circumstances. This is a version of 'reconstitutive downward causation' where system properties lead to changes in individual dispositions and capacities (Emmeche et al. 2000, Hodgson 2003, Hodgson and Knudsen 2005).

A relevant question is what are the characteristics of replicators that permit such an increase of complexity in the system as a whole? An attempt to answer this question is in another paper (Hodgson and Knudsen 2008). This paper argues that to enhance the potential for complexity in the system, the replicator must store instructions to guide the development of the relevant interactor. Consequently, the approach outlined here has a 'positive heuristic' that lays out new research questions and begins to provide some answers.

Such micro aspects of 'complex adaptive systems' are given less emphasis in much of the previous complexity literature. It is necessary to acknowledge that such systems are composed of populations of entities that face problems of complexity and survival in their local environments. Darwinism provides a meta-theoretical framework for beginning to analyse such systems from both a macro and a micro perspective. It does not provide all the answers and it always requires specific auxiliary theorising at every level. That is part of the beauty of Darwinism; it provides a multi-level, micro-macro perspective that does not claim to explain or predict everything. Yet with such complex population systems the Darwinian principles of inheritance, variety and selection are unavoidable. It is no exaggeration to claim that Darwin is one of the earliest and most important theorists of complexity.

\section{References}

Akerlof, George A. and Yellen, Janet L. (1985) 'A Near-Rational Model of the Business Cycle With Wage and Price Inertia', Quarterly Journal of Economics, 100(supplement), pp. 823-38.

Aldrich, Howard E., Geoffrey M. Hodgson, David L. Hull, Thorbjørn Knudsen, Joel Mokyr and Viktor J. Vanberg (2008) 'In Defence of Generalized Darwinism', Journal of Evolutionary Economics, 18(5), October, pp. 577-96. 
Aldrich, Howard E. and Ruef, Martin (2006) Organizations Evolving, second edition. (London: Sage).

Andersen, Esben Sloth (2004) 'Population Thinking, Price's Equation and the Analysis of Economic Evolution', Evolutionary and Institutional Economics Review, 1(1), November, pp. 127-48.

Anderson, Philip (1999) 'Complexity Theory and Organization Science', Organization Science, 10(3), May-June, pp. 216-32.

Arrow, Kenneth J. (1986) 'Rationality of Self and Others in an Economic System', Journal of Business, 59(4.2), October, pp. S385-S399.

Becker, Gary S. (1992) 'Habits, Addictions and Traditions', Kyklos, 45, Fasc. 3, pp. 327-46.

Blitz, David (1992) Emergent Evolution: Qualitative Novelty and the Levels of Reality (Dordrecht: Kluwer).

Camazine, Scott, Deneubourg, Jean-Luis, Franks, Nigel R., Sneyd, James, Theraulaz, Guy, and Bonabeau, Eric (2001) Self-Organization in Biological Systems (Princeton, NJ: Princeton University Press).

Camerer, Colin F. (2003) Behavioral Game Theory: Experiments in Strategic Interaction (Princeton: Princeton University Press).

Campbell, Donald T. (1965) 'Variation, Selection and Retention in Sociocultural Evolution', in Barringer, H. R., Blanksten, G. I. and Mack, R. W. (eds) (1965) Social Change in Developing Areas: A Reinterpretation of Evolutionary Theory (Cambridge, MA: Schenkman), pp. 19-49.

Cilliers, Paul (1998) Complexity and Postmodernism: Understanding Complex Systems (London: Routledge).

Cohen, Michael D. and Bacdayan, Paul (1994) 'Organizational Routines are Stored as Procedural Memory - Evidence from a Laboratory Study’, Organization Science, 5(4), November, pp. 554-68.

Cohen, Michael D., Burkhart, Roger, Dosi, Giovanni, Egidi, Massimo, Marengo, Luigi, Warglien, Massimo, and Winter, Sidney (1996) 'Routines and Other Recurring Action Patterns of Organizations: Contemporary Research Issues', Industrial and Corporate Change, 5(3), pp. 653-98.

Cziko, Gary (1995) Without Miracles: Universal Selection Theory and the Second Darwinian Revolution (Cambridge, MA: MIT Press).

Darwin, Charles R. (1859) On the Origin of Species by Means of Natural Selection, or the Preservation of Favoured Races in the Struggle for Life, $1^{\text {st }}$ edn. (London: Murray).

Darwin, Charles R. (1871) The Descent of Man, and Selection in Relation to Sex, $1^{\text {st }}$ edn., 2 vols (London: Murray and New York: Hill).

Dawkins, Richard (1976) The Selfish Gene (Oxford: Oxford University Press).

Depew, David J. and Weber, Bruce H. (1995) Darwinism Evolving: Systems Dynamics and the Genealogy of Natural Selection (Cambridge, MA: MIT Press).

Dewey, John (1922) Human Nature and Conduct: An Introduction to Social Psychology, 1st edn. (New York: Holt). 
Dosi, Giovanni, Marengo, Luigi, Bassanini, Andrea and Valente, Marco (1999) 'Norms as Emergent Properties of Adaptive Learning: The Case of Economic Routines', Journal of Evolutionary Economics, 9(1), pp. 5-26.

Dosi, Giovanni, Nelson, Richard R. and Winter, Sidney G. (2000) 'Introduction: The Nature and Dynamics of Organizational Capabilities' in Dosi, Giovanni, Nelson, Richard R. and Winter, Sidney G. (eds) (2000) The Nature and Dynamics of Organizational Capabilities (Oxford: Oxford University Press), pp. 1-22.

Drubach, Daniel (2000) The Brain Explained (Englewood Cliffs, NJ: Prentice-Hall).

Emmeche, Claus, Køppe, Simo and Stjernfelt, Frederik (2000) 'Levels, Emergence, and Three Versions of Downward Causation', in Andersen, Peter Bøgh, Emmeche, Claus, Finnemann, Niels Ole and Christiansen, Peder Voetman (eds) (2000) Downward Causation: Minds, Bodies and Matter (Aarhus: Aarhus University Press), pp. 13-34.

Gigerenzer, Gerd, Todd, Peter M. et al. (1999) Simple Heuristics That Make Us Smart (Oxford and New York: Oxford University Press).

Gintis, Herbert (2000) Game Theory Evolving: A Problem-Centered Introduction to Modeling Stategic Interaction (Princeton: Princeton University Press).

Godfrey-Smith, Peter (2000) 'The Replicator in Retrospect', Biology and Philosophy, 15, pp. 403-23.

Goodwin, Brian C. (1994) How the Leopard Changed Its Spots: The Evolution of Complexity (London: Weidenfeld and Nicholson).

Gould, Stephen Jay (2002) The Structure of Evolutionary Theory (Cambridge, MA: Harvard University Press).

Grandmont, Jean-Michel (ed.) (1987) Nonlinear Economic Dynamics (New York: Academic Press). Reprint of October 1986 issue of the Journal of Economic Theory.

Haltiwanger, John and Waldman, Michael (1985) 'Rational Expectations and the Limits of Rationality: An Analysis of Heterogeneity', American Economic Review, 75(3), September, pp. 159-73.

Hayek, Friedrich A. (1988) The Fatal Conceit: The Errors of Socialism. The Collected Works of Friedrich August Hayek, Vol. I, ed. William W. Bartley III (London: Routledge).

Hodgson, Geoffrey M. (1993) Economics and Evolution: Bringing Life Back Into Economics (Cambridge, UK and Ann Arbor, MI: Polity Press and University of Michigan Press).

Hodgson, Geoffrey M. (2001) How Economics Forgot History: The Problem of Historical Specificity in Social Science (London and New York: Routledge).

Hodgson, Geoffrey M. (2003) 'The Hidden Persuaders: Institutions and Individuals in Economic Theory', Cambridge Journal of Economics, 27(2), March, pp. 159-75.

Hodgson, Geoffrey M. (2004) The Evolution of Institutional Economics: Agency, Structure and Darwinism in American Institutionalism (London and New York: Routledge).

Hodgson, Geoffrey M. (2008). 'The Concept of a Routine', in Markus C. Becker (ed.) (2008) Handbook of Organizational Routines (Cheltenham UK and Northampton MA: Edward Elgar), pp. 3-14. 
Hodgson, Geoffrey M. and Knudsen, Thorbjørn (2004a) 'The Complex Evolution of a Simple Traffic Convention: The Functions and Implications of Habit', Journal of Economic Behavior and Organization, 54(1), pp. 19-47.

Hodgson, Geoffrey M. and Knudsen, Thorbjørn (2004b) 'The Firm as an Interactor: Firms as Vehicles for Habits and Routines', Journal of Evolutionary Economics, 14(3), July, pp. 281-307.

Hodgson, Geoffrey M. and Knudsen, Thorbjørn (2006) 'Why We Need a Generalized Darwinism: and Why a Generalized Darwinism is Not Enough', Journal of Economic Behavior and Organization, 61(1), September, pp. 1-19.

Hodgson, Geoffrey M. and Knudsen, Thorbjørn (2008) 'Information, Complexity and Generative Replication', Biology and Philosophy, 43(1), pp. 47-65.

Holland, John H. (1992) 'Complex Adaptive Systems', Daedalus, 121(1), Winter, pp, 17-30.

Horgan, John (1995) 'From Complexity to Perplexity', Scientific American, June, 272(6), pp. 104-9.

Hull, David L. (1988) Science as a Process: An Evolutionary Account of the Social and Conceptual Development of Science (Chicago: University of Chicago Press).

Hull, David L., Langman, Rodney E., and Glenn, Sigrid S. (2001) 'A General Account of Selection: Biology, Immunology and Behavior’, Behavioral and Brain Sciences, 24(3), June, pp. 511-73.

James, William (1890) The Principles of Psychology, 2 vols, (New York and London: Holt and Macmillan).

Johnson, Michael G. and Henley, Tracy B. (1990) Reflections on the Principles of Psychology: William James after a Century (Hillsdale NJ: Elrbaum Associates).

Kauffman, Stuart A. (1993) The Origins of Order: Self-Organization and Selection in Evolution (Oxford and New York: Oxford University Press).

Kauffman, Stuart A. (1995) At Home in the Universe: The Search for Laws of SelfOrganization and Complexity (Oxford and New York: Oxford University Press).

Knudsen, Thorbjørn (2004) 'General Selection Theory and Economic Evolution: The Price Equation and the Replicator/Interactor Distinction', Journal of Economic Methodology, 11(2), June, pp. 147-73.

Koza, John R. (1992) 'The Genetic Programming Paradigm: Genetically Breeding Populations of Computer Programs to Solve Problems', in B. Soucek (ed.) (1992) Dynamic, Genetic and Chaotic Programming (New York: Wiley).

Marion, Russ (1999) The Edge of Organization: Chaos and Complexity Theories of Formal Social Systems (Thousand Oaks, CA: Sage).

Metcalfe, J. Stanley (1998) Evolutionary Economics and Creative Destruction (London and New York: Routledge).

Mayr, Ernst (1991) One Long Argument: Charles Darwin and the Genesis of Modern Evolutionary Thought (Cambridge, MA and London: Harvard University Press and Allen Lane).

Morçöl, Göktuğ (2001) 'What Is Complexity Science? Postmodernist or Postpositivist?' Emergence, 3(1), April, pp. 104-119. 
Nelson, Richard R. (1991) 'Why Do Firms Differ, and How Does it Matter?', Strategic Management Journal, 12, Special Issue, Winter, pp. 61-74.

Nelson, Richard R. and Winter, Sidney G. (1982) An Evolutionary Theory of Economic Change (Cambridge, MA: Harvard University Press).

Ouellette, Judith A. and Wood, Wendy (1998) 'Habit and Intention in Everyday Life: The Multiple Processes by which Past Behavior Predicts Future Behavior', Psychological Bulletin, 124, pp. 54-74.

Plotkin, Henry C. (1994) Darwin Machines and the Nature of Knowledge: Concerning Adaptations, Instinct and the Evolution of Intelligence (Harmondsworth: Penguin).

Poldrack, Russell A., Clark, J., Pare-Blagoev, J., Shohamy, D., Creso Moyano, J., Myers, C. and Gluck, M. A. (2001) 'Interactive Memory Systems in the Human Brain', Nature, 414, 29 November, pp. 546-550.

Price, George R. (1995) 'The Nature of Selection', Journal of Theoretical Biology, 175, pp. 389-96.

Richerson, Peter J. and Boyd, Robert (2001) 'Built For Speed, Not for Comfort: Darwinian Theory and Human Culture', History and Philosophy of the Life Sciences, 23(3/4), pp. 423-63.

Ritchie, David G. (1896) 'Social Evolution', International Journal of Ethics, 6(2), pp. 165-81.

Saviotti, Pier Paolo (1996) Technological Evolution, Variety and the Economy (Aldershot: Edward Elgar).

Simon, Herbert A. (1957) Models of Man: Social and Rational. Mathematical Essays on Rational Human Behavior in a Social Setting (New York: Wiley).

Stacey, Ralph D. (1996) Complexity and Creativity in Organizations (San Francisco: BerrettKoehler).

Stacey, Ralph D. (2003) Strategic Management and Organisational Dynamics: The Challenge of Complexity, 4th ed. (Harlow: Prentice Hall).

Sterelny, Kim, Smith, Kelly C. and Dickison, Michael (1996) 'The Extended Replicator', Biology and Philosophy, 11, pp. 377-403.

Veblen, Thorstein B. (1898) 'Why Is Economics Not an Evolutionary Science?', Quarterly Journal of Economics, 12(3), July, pp. 373-97.

Veblen, Thorstein B. (1899) The Theory of the Leisure Class: An Economic Study in the Evolution of Institutions (New York: Macmillan).

Veblen, Thorstein B. (1914) The Instinct of Workmanship, and the State of the Industrial Arts (New York: Macmillan).

Weber, Bruce H. and Depew, David J. (1996) 'Natural Selection and Self-Organisation: Dynamical Models as Clues to a New Evolutionary Synthesis', Biology and Philosophy, 11(1), January, pp. 33-65.

Weissman, David (2000) A Social Ontology (New Haven, CT: Yale University Press).

Wicken, Jeffrey S. (1987) Evolution, Thermodynamics, and Information: Extending the Darwinian Paradigm (Oxford and New York: Oxford University Press). 
Winter, Sidney G., Jr (1964) 'Economic "Natural Selection” and the Theory of the Firm', Yale Economic Essays, 4(1), pp. 225-72.

Wolfram, Stephen (2002) A New Kind of Science (Champaign, IL: Wolfram Media).

Wood, Wendy and Neal, David T. (2007) 'A New Look at Habits and the Habit-Goal Interface', Psychological Review, 114(4), October, pp. 843-863.

Wood, Wendy, Quinn, Jeffrey M. and Kashy, D. (2002) 'Habits in Everyday Life: Thought, Emotion, and Action', Journal of Personality and Social Psychology, 83, pp. 1281-97. 